\title{
Gender differences in the impact of the Covid-19 lockdown on unpaid care work and psychological distress in the UK.
}

\author{
Baowen Xue ${ }^{a}$ and Anne McMunn ${ }^{a}$ \\ a UCL Research Department of Epidemiology \& Public Health \\ baowen.xue.10@ucl.ac.uk
}

20 August 2020

\begin{abstract}
School and nursery closures and homeworking during the Covid-19 crisis have resulted in an immediate increase in unpaid care work, particularly for parents. Amongst contemporary couples in the UK, women spent more time than men doing housework, childcare and caring for adults prior to the crisis; thus, lockdown draws new attention to gender inequality in divisions of unpaid care work. This study aims to answer how couples in the UK divided childcare and housework during lockdown and whether this is associated with changes in levels of psychological distress. Data for this study come from the April and May waves of Understanding Society Covid-19 study. Psychological distress was measured using the GHQ score (ranges from 0 to 36). Unpaid care work included men and women's hours spent on childcare and housework and the impact of increased unpaid care work on employment schedules. We found that every week, women spent 5 more hours on housework and 10 more hours on childcare than men during lockdown, and this increased housework and childcare was associated with higher levels of psychological distress for women. One-third of parents adapted their work patterns because of childcare/ homeschooling. Men and women who adapted their work patterns had on average 1.16 and 1.39 higher GHQ scores than those who did not. This association was much stronger if he or she was the only member in the household who adapted their work patterns, or if she was a lone mother. Only $10 \%$ of fathers reduced work hours due to care work compared to $20 \%$ of mothers. Fathers had more psychological distress if they reduced work hours but she did not, compared to neither reducing work hours. Our research suggests that lockdown has hit people with young families and lone mothers particularly hard in terms of mental health, and continued gender inequality in divisions of unpaid care work during lockdown may be putting women at a greater risk of psychological distress.
\end{abstract}

\section{Motivation}

Lockdown during the Covid-19 pandemic signified a fairly immediate increase in unpaid care work, particularly for families with young children, often combined with remote working from home. Unpaid care work is defined as all unpaid services provided within a household for its members, including care of persons and housework (Elson, 2000). Prior to the pandemic, recent evidence suggested that, amongst contemporary couples in the UK, women continue to spend more time than men doing housework, childcare and caring for adults (McMunn, Bird, Webb, \& Sacker, 2020) and initial survey data in the UK suggested that the increased domestic workload during lockdown has fallen more to women than to men (Andrew A, Cattan S, Costa Dias M, Farquharson C, Kraftman L, Krutikova S, Phimister A, 2020). In the short-term, juggling home working with homeschooling and childcare is likely to lead to long-hour days and working non-standard schedules for many parents. In the longerterm, increased unpaid care work may have implications for employment participation, pay and progression, exacerbating the persistent gender pay gap (Andrew A, Cattan S, Costa Dias $M$, Farquharson C, Kraftman L, Krutikova S, Phimister A, 2020). 
In addition, lone parents, the vast majority of whom are women, are at a greater risk of poverty and poor health (Burstrom et al., 2010) and already struggled to combine work and family responsibilities before the pandemic (Ridge \& Millar, 2011). Shutdowns and school and nursery closures during lockdown may exacerbate existing inequalities between couple parents and lone parents.

Combining employment with increased childcare, homeschooling and housework may have increased feelings of psychological distress through reduced time for sleep and leisure, and the stress of trying to meet competing demands. Previous work has documented the mental health effects of working non-standard hours (Weston, Zilanawala, Webb, Carvalho, \& McMunn, 2019), as well as combining care provision with full-time employment (Lacey, McMunn, \& Webb, 2019). A national survey of the UK during lockdown also showed that women's psychological distress rose more than men's during lockdown (Banks \& Xu, 2020).

The aim of this work is to use the unique household design of the UK Household Longitudinal Study data collections during April and May 2020 to ask:

1. How have couples in the UK divided homeschooling/childcare and housework between them during lockdown?

2. Is increased childcare/homeschooling and housework, gender divisions in this increased unpaid work, or the impact of increased unpaid care work on employment schedules associated with changes in levels of psychological distress pre- and post-lockdown?

3. Do these associations differ for men and women?

4. Do these associations differ for those who are living with a partner and those who are not?

\section{Data}

Data for this study come from the Understanding Society Covid-19 study. Understanding Society, also known as UK Household Longitudinal Study, is a nationally representative longitudinal study, which began in 2009 and recruited over 100,000 individuals in 40,000 households (Burton, J., Laurie, H., Lynn, 2011). From April 2020, participants from the last two waves (wave 8 and wave 9) of main Understanding Society sample have been invited to complete a short web-survey to understand the experiences and reactions of the UK population to the Covid-19 pandemic. Participants complete one web survey a month, which includes core content designed to track changes, alongside variable content adapted each month as the coronavirus situation develops. Our study uses the April ( $1^{\text {st }}$ wave) and the May ( $2^{\text {nd }}$ wave) waves. A total of 17,452 respondents (6,166 are parents) answered the April wave and 14,811 respondents answered the May wave. The overall response rate of April and May wave was $41.2 \%$ and $40.2 \%$, respectively. Among those who had given a full adult interview in the wave 9 annual main interview, the response rate of April and May wave was $48.6 \%$ and $49.1 \%$, respectively. The survey procedures are approved by the Ethics Committee of University of Essex. More details of the procedures can be found in the User Guide (Institute for Social and Economic Research, 2020).

\section{Sample}

We excluded participants with missing data on exposure, outcome or covariates. This study involves several different unpaid care work exposures. We included every participant (without missing data) to examine how housework influence people's mental health and well-being, while when analysing childcare or homeschooling, our sample is limited to parents who have one or more children age 18 or lower in the household. When analysing whether employment hours were reduced or adapted because of the time spent doing childcare or homeschooling, our sample is limited to parents who were working before the pandemic (i.e. self-reports of working hours is higher than zero in January or 
February). When analysing the gender division of unpaid care between couples (i.e., couple-level exposure), we further limited our sample to those who were living with a couple in the interview and both members having answered the relevant unpaid care questions.

\section{Measures}

\section{Unpaid care work}

Hours spent on doing housework in the last week and hours spent on childcare/homeschooling in the last week were measured in both April and May waves. Items asking whether employment hours were reduced or adapted because of the time spent doing childcare or homeschooling were added to the May wave on our request. In terms of couple-level exposures, women's share of involvement in housework or childcare was measured as the per cent of total time that the couple spends on housework or childcare being done by women $\times 100$. Whether employment hours were reduced or adapted between couples were grouped into neither, both, she only, and he only.

\section{Psychological distress}

Psychological distress was measured using the 12 -item General Health Questionnaire (GHQ). GHQ is a validated scale of measuring non-psychotic psychological distress and has been widely used in the community or non-clinical settings (Aalto, Elovainio, Kivimäki, Uutela, \& Pirkola, 2012). There are 12 items about respondents' depressive, anxiety symptoms, confidence and overall happiness, and each item has four response categories on a Likert scale ( 0 'less than usual', 1 'no more than usual', 2 'rather more than usual', and 3 'much more than usual'). Scores are summed and range from 0 (least distressed) to 36 (most distressed).

\section{Confounders}

In order to test the changes in levels of psychological distress, we adjusted for baseline GHQ scores, which was measured in wave 9 main survey. We have controlled for a number of socio-demographic characteristics. Participants' age was adjusted as a categorical variable (16/24, 25/34, 35/44, 45/54, $55 / 64,65 / 74,75+)$. We also controlled for ethnicity (White, Indian/Pakistani/Bangladeshi/ Chinese/Arab/ any other Asian background, African/Black/Caribbean, and other/mixed), whether living with a partner or not, and the number of children in the household $(0,1,2+)$ by children's age group (aged 0-4, 5-15 and 16-18). Participants were asked to recall their working hours before the pandemic (in January or February 2020), so baseline working hour was adjusted as a categorical variable (not working, working part-time which is $<30 \mathrm{~h} / \mathrm{w}$, working full-time which is 30 to $40 \mathrm{~h} / \mathrm{w}$, and working full-time with long hours which is higher than $40 \mathrm{~h} / \mathrm{w}$ ). Information on educational qualification and occupational class were not collected in the Covid survey, and thus, data from wave 9 main survey was used. Highest educational qualification was categorised as degree (International Standard Classification of Education-ISCED level 6), higher education below degree (ISCED level 4 and 5), A-level (ISCED level 3), O-level (ISCED level 2), and lower than O-level. Occupational class was measured by the National Statistics Socio-economic Classification (NS-SEC) five-class version (management \& professional, intermediate, small employers \& own account, lower supervisory \& technical, and semi-routine \& routine). Those who were not working in January or February, their occupational class was coded as 'not working in Jan/Feb'. Those who were working in January or February but not in wave 9 (and thus have no information of occupational class) were coded as 'not working in wave 9 only'. April wave only measured household earnings (i.e., earnings from paid work or self-employment), but not household income (e.g. pension among those not working). Therefore, quintiles of total household net income from wave 9 main survey were used. 


\section{Statistical analyses}

We did two cross-sectional analyses using the April wave and May wave, separately. All the analyses were stratified by gender as we are interested in the gender differences, and our pooled analyses showed that gender was a statistically significant $(p<0.01)$ effect modifier in the association between unpaid care work and GHQ.

The association between unpaid care work and GHQ Likert scores was assessed by linear regression models, as GHQ Likert scores are normally distributed in the sample. All the regression model analyses were weighted (Stata command 'svyset') to take account of cross-sectional probability weight, clustering (primary sampling unit) and stratification (strata) at wave 9 main survey. This will provide estimates that are representative of the population of all adults $(16+)$ resident in private households in the UK at the time of wave 9 main survey.

To answer our research question 4, we tested whether living with a partner is an effect modifier using an interaction term between partnership status and unpaid care variables, and stratified analyses were conducted if living with a partner was a statistically significant effect modifier.

\section{Results}

\section{Descriptive results}

Table 1 shows sample characteristics by gender and by wave. The April and May samples have very similar characteristics. Compared to women, men were older and were more likely to live with a partner, although they were slightly less likely to have a child in the household. Men were also more likely to work full-time or work full-time with long hours before the pandemic, were more likely to have a degree qualification, to be in a management \& professional occupational class, to have higher household income and to have lower baseline GHQ score (i.e., better mental health) than women. The distributions of ethnicity are the same between men and women.

Table 2 shows the gender division of unpaid care work in April and May. On average, women spent about 15 hours per week doing housework in April and May, while men spent less than 10 hours per week on doing housework. Regarding childcare, women spent on average 20.5 hours per week on childcare/homeschooling in April, and this number increased to 22.5 hours per week in May. Men spent about 12 hours per week on childcare/homeschooling in April and May. Because of the time spent on doing childcare/ homeschooling, one in six women reduced their employment hours and one in three women adapted their work patterns. Men were $5 \%$ less likely to reduce working hours and $7 \%$ to less likely to adapt work patterns due to childcare/ homeschooling than women.

Between couples, women shared $64 \%$ of housework and $63 \%$ of childcare. Most couple parents did not reduce their employment hours due to childcare/ homeschooling ( $65 \%$ neither), but women were more likely than men to reduce their employment hours as a result of childcare/homeschooling ( $21 \%$ she only and $11 \%$ he only). Only $4 \%$ of couples both reduced their employment hours. While many more couple parents adapted their work patterns because of childcare/ homeschooling, the patterns were similar to those for reducing employment hours although there were more couples who both changed their employment patterns ( $32 \%$ she only, $18 \%$ he only, $14 \%$ both, and $35 \%$ neither).

\section{Regression results}

Table 3 shows the association between unpaid care work and GHQ for men and women in April in adjusted models. It shows that increased housework hours and childcare/ homeschooling hours were associated with higher levels of psychological distress among women only. Among women, every one- 
hour increase in housework hours per week was associated with 0.05 higher scores on the 36-point scale of GHQ, and every one-hour increase in childcare/ homeschooling hours per week was associated with 0.02 higher scores of GHQ. No such statistically significant association was found among men. Between couples, women's share of involvement in housework and childcare/homeschooling was associated with neither men's nor women's GHQ.

Table 4 shows the fully adjusted association between unpaid care work and GHQ for men and women in May. Similar to the April results, increased childcare/ homeschooling hours were associated with higher levels of psychological distress among women only ((coef. $=0.02)$, but the association between housework hours and GHQ reduced to a non-significant level (coef. $=0.01$ ) in May. Again, women's share of involvement in housework and childcare/homeschooling was associated with neither men's nor women's GHQ. The May wave additionally measured whether employment hours were reduced or adapted because of childcare/ homeschooling. Men and women who adapted their work patterns due to childcare/ homeschooling had on average 1.16 and 1.39 higher GHQ scores than those who did not, respectively. This association became much stronger if he or she was the only member in the household who adapted work patterns. The coefficient was 2.48 if he only and 1.82 if she only adapted their work patterns, compared to couple neither adapted their work patterns. Men were more likely to have a higher GHQ score if he was the only member in the household who reduced working hours due to childcare/homeschooling (coef.=2.91 vs. neither reducing work hours).

\section{Partnership Differences}

Partnership significantly moderated $(p<0.05)$ the association between adapting work patterns and GHQ among women. Therefore, Table 5 shows the results stratified by lone mothers and couple mothers. Lone mothers who adapted work patterns due to childcare/ homeschooling had on average 3.93 higher GHQ scores than lone mothers who did not adapt work patterns. Adapting work patterns due to childcare/ homeschooling was not associated with couple mother's GHQ.

\section{Discussion}

Using a large, nationally representative study of UK adults, this study assessed the gender division of unpaid care work at both individual and couple level during lockdown and tested how it was associated with changes in levels of psychological distress pre- and post-lockdown for men and women.

We start by providing evidence that women spent much more time on doing housework and childcare than men during lockdown, and women's share of unpaid work is as much as $64 \%$ within couples. In addition, women were more likely than men to reduce working hours and to adapt employment schedules due to increased time on unpaid care. This suggests that the Covid-19 crisis did not force trends of gender convergence on unpaid work, and our result is consistent with previous research showing continued gender inequality in divisions of unpaid care work among UK couples before the crisis (McMunn et al., 2020). More importantly, we found that increased time spent on doing housework and childcare was associated with higher levels of psychological distress for women only. This suggests that women are more affected by the increased responsibilities at home during lockdown in terms of mental health.

Our results show that lockdown may hit working people with young families particularly hard, as onethird of parents in this study adapted their work patterns because of childcare/ homeschooling, and we found that men and women who adapted their work patterns to account for increased childcare/homeschooling hours had higher levels of psychological distress than those who did not. Fewer parents have reduced their working hours due to childcare/ homeschooling, and it is likely that many of parents are not able to reduce working hours in the context of potential increases in 
unemployment and redundancy during the crisis (Blundell, Costa Dias, Joyce, \& Xu, 2020). As suggested by the work-family conflict hypothesis, family and work responsibilities inevitable compete for time (Xue, Fleischmann, Head, Mcmunn, \& Stafford, 2020). When reducing working hours is not feasible, adapting work patterns, such as working late into the evenings, early mornings or weekends, become an option for many parents with young children. This may lead to poor sleep quality (Kalmbach, Pillai, Cheng, Arnedt, \& Drake, 2015; Virtanen et al., 2009), lack of physical exercise, feelings of loneliness and being overwhelmed as well as psychological distressed (Vogel, Braungardt, Meyer, \& Schneider, 2012). Our research shows that levels of psychological distress are particularly high if he or she was the only member in the household who adapted work patterns. Among dualearner couples, it may be that the one who has to adapt their work patterns feels a sense of injustice and distressed.

We found that living with a partner provides a significant buffer in the association between adapting work patterns and psychological distress among women and adapting one's work patterns due to childcare/ homeschooling seems to be more harmful for lone mothers than for couple mothers. Many working lone mothers already struggled to combine work and family responsibilities before the pandemic (Ridge \& Millar, 2011). The shut-down of formal childcare and rules of social distance mean that lone mothers juggle the pressure of being the sole breadwinner and childcarer which seems to be particularly linked with high levels of psychological distress. Increased responsibilities at home during lockdown have made it even harder for lone mothers to continue working and this may have knock-ons for their return to work or further hardship as they try to juggle uncertain times ahead.

\section{Strengths and Limitations}

In this study, a large, nationally representative sample of men and women from across the entire adult age range were analysed and we were able to account for a number of important covariates using the information from the wave 9 main survey. We included several detailed measures of unpaid care, at both individual and couple level. However, this study has several limitations. First, our analyses are cross-sectional, so we cannot estimate the causal effect of gender divisions of unpaid work on people's mental health. We have adjusted for baseline GHQ before the pandemic, so we were able to examine changes in GHQ scores and thus largely reduce the bias caused by reverse causality. Second, the Covid19 web surveys have relatively lower response rates (at about 40\%) than the main annual survey, and participants who do not use the internet were not included in the sample. It is possible that those were most affected by the lockdown did not participate in the Covid-19 web surveys, and thus our results may be underestimated. In addition, when assessing the couple-level division of domestic labour, our sample is limited to those who are living with a couple in the interview and both members having answered the relevant unpaid care questions. So, we were not able to measure the couplelevel division of unpaid care if only one member of the couple has participated in the survey, leading to selection bias as well.

\section{Conclusion}

Our research suggests that lockdown has hit people with young families and lone mothers particularly hard in terms of mental health. Continued gender inequality in divisions of unpaid care work during lockdown may put women at a greater risk of psychological distress. Awareness of continued gender biases in divisions of labour and their impact on psychological health is important for both couples and employers going forward. 
Table 1. Descriptive characteristics of men and women ${ }^{a}$

\begin{tabular}{|c|c|c|c|c|}
\hline & \multicolumn{2}{|c|}{ April wave } & \multicolumn{2}{|c|}{ May wave } \\
\hline & $\begin{array}{c}\text { Men } \\
\mathrm{N}=6419 \\
\%\end{array}$ & $\begin{array}{c}\text { Women } \\
\mathrm{N}=9007 \\
\%\end{array}$ & $\begin{array}{c}\text { Men } \\
\mathrm{N}=5859 \\
\%\end{array}$ & $\begin{array}{c}\text { Women } \\
\begin{array}{c}\mathrm{N}=8291 \\
\%\end{array}\end{array}$ \\
\hline \multicolumn{5}{|l|}{ Age-group } \\
\hline $16 / 25$ & 5.9 & 8.4 & 4.5 & 7.5 \\
\hline $25 / 34$ & 9.0 & 11.4 & 8.2 & 10.6 \\
\hline $35 / 44$ & 14.1 & 16.2 & 13.6 & 15.7 \\
\hline $45 / 54$ & 20.1 & 20.6 & 19.9 & 20.7 \\
\hline $55 / 64$ & 21.8 & 20.7 & 22.4 & 21.3 \\
\hline $65 / 74$ & 20.0 & 16.4 & 21.6 & 17.5 \\
\hline $75+$ & 9.2 & 6.2 & 9.9 & 6.7 \\
\hline \multicolumn{5}{|l|}{ Ethnicity } \\
\hline White & 83.6 & 82.9 & 84.9 & 83.7 \\
\hline Other Asian & 6.1 & 5.7 & 5.9 & 5.9 \\
\hline African/Black/Caribbean & 1.9 & 2.6 & 2.0 & 2.6 \\
\hline Other/mixed & 1.2 & 1.1 & 1.0 & 1.1 \\
\hline Missing & 7.3 & 7.7 & 6.1 & 6.7 \\
\hline \multicolumn{5}{|l|}{ Living with a partner } \\
\hline Yes & 77.7 & 67.6 & 76.0 & 66.0 \\
\hline No & 22.3 & 32.4 & 24.0 & 34.0 \\
\hline \multicolumn{5}{|l|}{ Number of children aged 0-4 } \\
\hline 0 & 92.4 & 90.3 & 92.4 & 91.6 \\
\hline 1 & 6.6 & 7.6 & 6.1 & 6.7 \\
\hline $2+$ & 2.0 & 2.0 & 1.6 & 1.8 \\
\hline \multicolumn{5}{|l|}{ Number of children aged 5-15 } \\
\hline 0 & 78.9 & 75.6 & 79.8 & 76.8 \\
\hline 1 & 11.2 & 12.9 & 11.0 & 12.3 \\
\hline $2+$ & 9.9 & 11.5 & 9.2 & 10.8 \\
\hline \multicolumn{5}{|l|}{ Number of children aged $16-18$} \\
\hline 0 & 90.7 & 89.5 & 92.1 & 90.5 \\
\hline 1 & 8.4 & 9.3 & 7.5 & 8.7 \\
\hline $2+$ & 0.8 & 1.2 & 0.5 & 0.8 \\
\hline \multicolumn{5}{|l|}{ Baseline working hours } \\
\hline Not working & 37.2 & 38.0 & 38.7 & 38.9 \\
\hline Working PT & 7.6 & 23.0 & 7.8 & 22.5 \\
\hline Working FT & 40.1 & 33.6 & 38.4 & 33.0 \\
\hline Working FT with long hours & 15.0 & 5.3 & 14.9 & 5.4 \\
\hline Missing & 0.1 & 0.2 & 0.1 & 0.1 \\
\hline \multicolumn{5}{|l|}{ Qualifications } \\
\hline Degree & 34.2 & 31.0 & 34.9 & 31.8 \\
\hline Higher education below degree & 11.1 & 14.8 & 11.5 & 14.8 \\
\hline A-level & 10.9 & 10.7 & 10.5 & 10.7 \\
\hline O-level & 19.0 & 20.1 & 19.0 & 19.9 \\
\hline Lower & 16.8 & 15.0 & 17.3 & 15.4 \\
\hline Missing & 8.0 & 8.4 & 6.8 & 7.4 \\
\hline
\end{tabular}




\begin{tabular}{lcccc}
\hline Occupational class & & & & \\
Management \& professional & 28.5 & 24.6 & 28.1 & 25.1 \\
Intermediate & 5.2 & 9.2 & 4.8 & 9.2 \\
Small employers \& own account & 5.7 & 3.4 & 5.8 & 3.4 \\
Lower supervisory \& technical & 4.5 & 1.8 & 4.4 & 1.8 \\
Semi-routine \& routine & 8.6 & 11.4 & 8.5 & 10.8 \\
Not working in Jan/Feb & 37.2 & 38.0 & 38.7 & 38.9 \\
Not working in wave 9 only & 7.7 & 9.4 & 7.0 & 8.6 \\
Missing & 2.6 & 2.2 & 2.6 & 2.2 \\
Household income & & & & \\
Lowest & 16.9 & 20.3 & 17.1 & 20.4 \\
2 & 19.2 & 18.5 & 19.5 & 18.5 \\
3 & 19.4 & 18.9 & 19.6 & 18.8 \\
4 & 20.2 & 18.1 & 20.2 & 18.2 \\
Highest & 20.1 & 18.1 & 19.7 & 18.7 \\
Missing & 4.3 & 6.1 & 4.1 & 5.4 \\
Mean GHQ (SD) & $11.22(5.42)$ & $13.32(6.30)$ & $11.27(5.49)$ & $13.02(6.15)$ \\
Mean baseline GHQ (SD) & $10.38(4.97)$ & $11.61(5.62)$ & $10.01(5.44)$ & $11.27(5.97)$ \\
\% missing & 8.7 & 9.0 & 5.9 & 6.6 \\
\hline
\end{tabular}

${ }^{\mathrm{a}} \mathrm{N}$ is based on sample who has both $\mathrm{GHQ}$ and housework data

Table 2. Descriptive characteristics of gender division of unpaid care work ${ }^{a}$

\begin{tabular}{|c|c|c|c|c|}
\hline \multirow[b]{2}{*}{ Individual-level domestic work } & \multicolumn{2}{|c|}{ April wave } & \multicolumn{2}{|c|}{ May wave } \\
\hline & Men & Women & Men & Women \\
\hline Housework hours per week (mean) & 9.91 & 14.92 & 9.55 & 14.87 \\
\hline Childcare/homeschooling hours per week (mean) & 12.03 & 20.54 & 11.61 & 22.47 \\
\hline $\begin{array}{l}\text { Reduce employment hours due to childcare/ } \\
\text { homeschooling }\end{array}$ & -- & -- & $11.6 \%$ & $16.8 \%$ \\
\hline $\begin{array}{l}\text { Adapted work patterns due to childcare/ } \\
\text { homeschooling }\end{array}$ & -- & -- & $29.5 \%$ & $36.7 \%$ \\
\hline Couple-level domestic work & \multicolumn{2}{|c|}{ April wave } & \multicolumn{2}{|c|}{ May wave } \\
\hline Women's share of housework & \multicolumn{2}{|c|}{$63.5 \%$} & \multicolumn{2}{|c|}{$64.1 \%$} \\
\hline $\begin{array}{l}\text { Women's share of childcare/ } \\
\text { homeschooling }\end{array}$ & \multicolumn{2}{|c|}{$62.2 \%$} & \multicolumn{2}{|c|}{$63.1 \%$} \\
\hline \multicolumn{5}{|l|}{$\begin{array}{l}\text { Reduce employment hours due to childcare/ } \\
\text { homeschooling }\end{array}$} \\
\hline Neither & \multicolumn{2}{|r|}{--} & \multicolumn{2}{|c|}{$64.9 \%$} \\
\hline Both & \multicolumn{2}{|r|}{--} & \multicolumn{2}{|c|}{$3.5 \%$} \\
\hline She only & \multicolumn{2}{|r|}{--} & \multicolumn{2}{|c|}{$21.1 \%$} \\
\hline He only & \multicolumn{2}{|r|}{--} & \multicolumn{2}{|c|}{$10.6 \%$} \\
\hline \multicolumn{5}{|l|}{$\begin{array}{l}\text { Adapted work patterns due to childcare/ } \\
\text { homeschooling }\end{array}$} \\
\hline Couple neither & \multicolumn{2}{|r|}{--} & \multicolumn{2}{|c|}{$35.4 \%$} \\
\hline Couple both & \multicolumn{2}{|r|}{--} & \multicolumn{2}{|c|}{$14.2 \%$} \\
\hline She only & \multicolumn{2}{|r|}{--} & \multicolumn{2}{|c|}{$32.4 \%$} \\
\hline He only & \multicolumn{2}{|r|}{-- } & \multicolumn{2}{|c|}{$18.0 \%$} \\
\hline
\end{tabular}

${ }^{a}$ based on sample who has both GHQ and interested unpaid work variable 
Table 3. Association between unpaid care work and GHQ in April wave a

\begin{tabular}{|c|c|c|c|c|c|c|}
\hline & \multicolumn{3}{|c|}{ GHQ Likert, Men } & \multicolumn{3}{|c|}{ GHQ Likert, Women } \\
\hline & Coef. & p-value & $\mathbf{N}$ & Coef. & p-value & $\mathbf{N}$ \\
\hline \multicolumn{7}{|l|}{ Individual-level domestic work } \\
\hline Housework hours per week & 0.024 & 0.112 & 5541 & 0.045 & 0.001 & 7677 \\
\hline Childcare/homeschooling hours per week & 0.022 & 0.160 & 1582 & 0.022 & 0.006 & 2592 \\
\hline \multicolumn{7}{|l|}{ Couple-level domestic work } \\
\hline Women's share of housework & 0.003 & 0.629 & 3880 & 0.004 & 0.685 & 3129 \\
\hline $\begin{array}{l}\text { Women's share of } \\
\text { childcare/homeschooling }\end{array}$ & -0.001 & 0.936 & 849 & 0.004 & 0.765 & 883 \\
\hline
\end{tabular}


Table 4. Association between unpaid care work and GHQ in May wave ${ }^{\text {a }}$

\begin{tabular}{|c|c|c|c|c|c|c|}
\hline & \multicolumn{3}{|c|}{ GHQ Likert, Men } & \multicolumn{3}{|c|}{ GHQ Likert, Women } \\
\hline & Coef. & p-value & $\mathbf{N}$ & Coef. & p-value & $\mathbf{N}$ \\
\hline \multicolumn{7}{|l|}{ Individual-level domestic work } \\
\hline Housework hours per week & 0.026 & 0.116 & 5202 & 0.013 & 0.234 & 7270 \\
\hline $\begin{array}{l}\text { Childcare/homeschooling hours per week } \\
\text { Reduced employment hours due to } \\
\text { childcare/homeschooling }\end{array}$ & 0.016 & 0.206 & 1417 & 0.018 & 0.036 & 2302 \\
\hline No & ref & & 1252 & ref & & 1738 \\
\hline Yes & 1.342 & 0.126 & & 0.655 & 0.233 & \\
\hline $\begin{array}{l}\text { Adapted work patterns due to childcare/ } \\
\text { homeschooling }\end{array}$ & & & 1250 & & & 1733 \\
\hline No & ref & & & ref & & \\
\hline Yes & 1.155 & 0.009 & & 1.393 & 0.006 & \\
\hline \multicolumn{7}{|l|}{ Couple-level domestic work } \\
\hline Women's share of housework & -0.005 & 0.524 & 2814 & -0.011 & 0.185 & 2842 \\
\hline $\begin{array}{l}\text { Women's share of } \\
\text { childcare/homeschooling }\end{array}$ & 0.001 & 0.880 & 766 & 0.015 & 0.101 & 785 \\
\hline $\begin{array}{l}\text { Reduced employment hours due to } \\
\text { childcare/homeschooling }{ }^{\mathrm{b}}\end{array}$ & & & 752 & & & 820 \\
\hline Neither & ref & & & ref & & \\
\hline Both & -0.715 & 0.358 & & 0.113 & 0.939 & \\
\hline She only & -0.731 & 0.231 & & 0.812 & 0.136 & \\
\hline He only & 2.913 & $<0.001$ & & 0.001 & 0.999 & \\
\hline $\begin{array}{l}\text { Adapted work patterns due to childcare/ } \\
\text { homeschooling }\end{array}$ & & & 834 & & & 957 \\
\hline Couple neither & ref & & & ref & & \\
\hline Couple both & 0.814 & 0.172 & & 0.726 & 0.551 & \\
\hline She only & 0.566 & 0.439 & & 1.821 & 0.002 & \\
\hline He only & 2.484 & $<0.001$ & & 0.626 & 0.551 & \\
\hline
\end{tabular}

${ }^{a}$ Adjusted for age, ethnicity, living with a partner, number of children in the household by children's age group, baseline working hours, qualifications, occupational class, and baseline GHQ. $p<0.05$ are show in bold.

Table 5. Association between adapting work patterns and GHQ stratified by couple mothers and lone mothers ${ }^{a}$

\begin{tabular}{lccccccc}
\hline & \multicolumn{2}{c}{ GHQ Likert, couple mothers } & \multicolumn{2}{c}{ GHQ Likert, lone mothers } \\
& Coef. & p-value & $\mathbf{N}$ & Coef. & p-value & $\mathbf{N}$ \\
\cline { 2 - 7 } $\begin{array}{l}\text { Adapted work patterns due } \\
\text { to childcare/homeschooling }\end{array}$ & & & & & & & \\
No & ref & & & & ref & & \\
Yes & 0.962 & 0.068 & 1413 & $\mathbf{3 . 9 3 1}$ & 0.001 & 320 \\
\hline
\end{tabular}

${ }^{a}$ Adjusted for age, ethnicity, number of children in the household by children's age group, baseline working hours, qualifications, occupational class, and baseline GHQ. $p<0.05$ are show in bold. 


\section{References}

Aalto, A. M., Elovainio, M., Kivimäki, M., Uutela, A., \& Pirkola, S. (2012). The Beck Depression Inventory and General Health Questionnaire as measures of depression in the general population: A validation study using the Composite International Diagnostic Interview as the gold standard. Psychiatry Research, 197(1-2), 163-171. https://doi.org/10.1016/j.psychres.2011.09.008

Andrew A, Cattan S, Costa Dias M, Farquharson C, Kraftman L, Krutikova S, Phimister A, S. A. (2020). How are mothers and fathers balancing work and family under lockdown? IFS Briefing Note NB290. London.

Banks, J., \& Xu, X. (2020). The mental health effects of the first two months of lockdown and social distancing during the Covid-19 pandemic in the UK. (W20 No. 16). London.

Blundell, R., Costa Dias, M., Joyce, R., \& Xu, X. (2020). COVID-19 and Inequalities*. Fiscal Studies, 41(2), 291-319. https://doi.org/10.1111/1475-5890.12232

Burstrom, B., Whitehead, M., Clayton, S., Fritzell, S., Vannoni, F., \& Costa, G. (2010). Health inequalities between lone and couple mothers and policy under different welfare regimes - The example of Italy, Sweden and Britain. Social Science and Medicine, 70(6), 912-920. https://doi.org/10.1016/j.socscimed.2009.11.014

Burton, J., Laurie, H., Lynn, P. (2011). Appendix: Understanding society design overview. In S. McFall (Ed.), Understanding society: Early findings from the first wave of the UK's household longitudinal study (pp. 129-140). Colchester, Essex, UK: Understanding Society, Institute for Social and Economic Research, University of Essex.

Elson, D. (2000). Progress of the World's Women 2000. In UNIFEM Biennial Report. New York.

Institute for Social and Economic Research. (2020). Understanding Society COVID-19 User Guide. Version 3.0, July 2020. Colchester: University of Essex.

Kalmbach, D. A., Pillai, V., Cheng, P., Arnedt, J. T., \& Drake, C. L. (2015). Shift work disorder, depression, and anxiety in the transition to rotating shifts: The role of sleep reactivity. Sleep Medicine, 16(12), 1532-1538. https://doi.org/10.1016/j.sleep.2015.09.007

Lacey, R. E., McMunn, A., \& Webb, E. (2019). Informal caregiving patterns and trajectories of psychological distress in the UK Household Longitudinal Study. Psychological Medicine, 49(10), 1652-1660. https://doi.org/10.1017/\$0033291718002222

McMunn, A., Bird, L., Webb, E., \& Sacker, A. (2020). Gender Divisions of Paid and Unpaid Work in Contemporary UK Couples. Work, Employment and Society, 34(2), 155-173. https://doi.org/10.1177/0950017019862153

Ridge, T., \& Millar, J. (2011). Following Families: Working Lone-Mother Families and their Children. Social Policy \& Administration, 45(1), 85-97. https://doi.org/10.1111/j.14679515.2010.00755.x

Virtanen, M., Ferrie, J. E., Gimeno, D., Vahtera, J., Elovainio, M., Singh-Manoux, A., ... Kivimäki, M. (2009). Long working hours and sleep disturbances: The whitehall II prospective cohort study. Sleep, 32(6), 737-745. https://doi.org/10.1093/sleep/32.6.737

Vogel, M., Braungardt, T., Meyer, W., \& Schneider, W. (2012, October 10). The effects of shift work on physical and mental health. Journal of Neural Transmission. Springer. https://doi.org/10.1007/s00702-012-0800-4

Weston, G., Zilanawala, A., Webb, E., Carvalho, L. A., \& McMunn, A. (2019). Long work hours, 
weekend working and depressive symptoms in men and women: Findings from a UK population-based study. Journal of Epidemiology and Community Health, 73(5), 465-474. https://doi.org/10.1136/jech-2018-211309

Xue, B., Fleischmann, M., Head, J., Mcmunn, A., \& Stafford, M. (2020). Work-Family Conflict and Work Exit in Later Career Stage. J Gerontol B Psychol Sci Soc Sci, 75(3), 716-727. https://doi.org/10.1093/geronb/gby146 